\title{
Adsorptive Performance of Ni(II) from Aqueous Solutions Using Biochar Made of Phragmites australis by Adding Ammonium Polyphosphate as Flame Retardant
}

\author{
Peng Liu, ${ }^{1}$ Min Yue, ${ }^{1}$ and Houyong Zhang ${ }^{2}$ \\ ${ }^{1}$ School of Environment Science and Engineering, Shandong University, Jinan 250100, China \\ ${ }^{2}$ Jinan Environmental Monitoring Center, Jinan 250014, China \\ Correspondence should be addressed to Min Yue; sduyuem@gmail.com
}

Received 11 December 2015; Accepted 9 February 2016

Academic Editor: Maria Roca

Copyright (C) 2016 Peng Liu et al. This is an open access article distributed under the Creative Commons Attribution License, which permits unrestricted use, distribution, and reproduction in any medium, provided the original work is properly cited.

The withered Phragmites australis (PA) surrounding the rivers can cause the secondary pollution of water. In this research, by changing the ratio $(R)$ of ammonium polyphosphate (APP), used as flame retardant, to PA at different temperatures, a series of BC samples were prepared for further analysis in several perspectives, namely, surface morphologies, surface areas, surface functional groups, and yields. The analysis indicated that, after being charred, the produced BCs obtained enhanced yields and promoted surface acidity. As adsorbent to remove $\mathrm{Ni}$ (II) from aqueous solutions, the BCs with APP improved the sorption of $\mathrm{Ni}(\mathrm{II})$ dramatically, compared with those purely produced by pyrolysis of $\mathrm{PA}$, and obtained the maximum of adsorption capacity with the $R$ of 0.25 at $400^{\circ} \mathrm{C}$.

\section{Introduction}

Biochar (BC), a kind of porous carbon material, is carbonization by biomass in anoxic or anaerobic conditions at low temperature. It has been widely used in carbon emission reduction, water purification, adsorption of heavy metals, and soil improvement $[1,2]$. In winter, the withered Phragmites australis (PA) played a negative role in normal operation of the constructed wetland and the secondary pollution of water [3]. Therefore, the withered PA is used to produce biochar, which will be a "turning waste into wealth" method [4]. In order to enhance the yields and properties of $\mathrm{BC}$, the common method is adding flame retardants. Ammonium polyphosphate (APP), a kind of excellent performance flame retardant, contains many advantages such as avirulent, insipidity, no corrosive gas produced, less hygroscopicity, and high thermal stability [5]. APP has been gradually used for the compound fertilizer and liquid fertilizer production and especially has been widely used in the developed countries. It is a good try to use APP as flame retardants for producing BC.

This research is designed (1) to evaluate the feasibility of APP as flame retardants for produced BC; (2) to study the effect of additive amount of APP and charring temperature $\left(300,400\right.$, and $\left.500^{\circ} \mathrm{C}\right)$ on the textural and chemical properties of produced $\mathrm{BCs}$; and (3) to evaluate the sorption capacities of produced $\mathrm{BCs}$ toward $\mathrm{Ni}(\mathrm{II})$ by comparing with the BCs derived from pyrolysis of PA without adding APP.

\section{Materials and Methods}

2.1. Materials and Chemical Reagents. Phragmites australis $(P A)$, with porous caudex system and large cell gap, can be used as a low-cost and efficient precursor for BC production. The PA grew in wetlands in Shandong, a province located in the eastern part of China. After being reaped in winter, the PA was washed in distilled water for a few times and aired in a $105^{\circ} \mathrm{C}$ environment for 24 hours and then smashed into pieces of approximately $0.45-1.0 \mathrm{~mm}$ [6]. Ammonium polyphosphate (APP) was used as flame retardant. By dissolving a weighted quantity of $\mathrm{NiCl}_{2} \cdot 5 \mathrm{H}_{2} \mathrm{O}$ in distilled water, the $\mathrm{Ni}(\mathrm{II})$ solution was obtained. All chemical reagents used were of analytical grade. 
2.2. Preparation of Activated Carbons. About $10 \mathrm{~g}$ PA were fully mixed with a weighted amount of APP and $10 \mathrm{~mL}$ distilled water, and the mixed samples were then aired in a $105^{\circ} \mathrm{C}$ environment for 12 hours to evaporate the moisture. The ratios ( $R, \mathrm{~g} \mathrm{APP} / \mathrm{g} \mathrm{PA})$ were $0,0.25,0.5$, and 1.0 , respectively. After being dried, the samples were placed in $150 \mathrm{~mL}$ ceramic crucibles, and each ceramic crucible was covered with a fitting lid. Then these samples were charred at 300,400 , and $500^{\circ} \mathrm{C}$ for 1 hour under $\mathrm{N}_{2}$ flow of $500 \mathrm{~mL} / \mathrm{min}$ in the muffle furnace (combustion chamber, $300 \mathrm{~mm} \times 200 \mathrm{~mm} \times 120 \mathrm{~mm}$ ), respectively [7]. In order to assess the impacts of APP on the final $\mathrm{BCs}$, another three BC samples without APP were prepared at the charring temperatures of 300,400 , and $500^{\circ} \mathrm{C}$ for 1 hour. After being cooled to room temperature, the charred residues were pulverized for subsequent demineralization with $0.1 \mathrm{~mol} / \mathrm{L} \mathrm{HCl}$. The samples were thoroughly washed in distilled water until $\mathrm{pH}$ of the washing liquid attained and kept a constant degree and then aired for 9 hours at a $105^{\circ} \mathrm{C}$ environment. These $\mathrm{BC}$ samples were hereafter referred to as $\mathrm{BC}-X-Y \mathrm{~s}$, in which $X$ and $Y$ represent the final charring temperature and the $R$, respectively.

2.3. Characterization Methods. The thermogravimetric analysis (TGA) and derivative thermogravimetric (DTG) curves of PA and the different impregnations mixture of PA and APP were derived from a thermogravimetric analysis (TGA50 analyzer). The PA samples were referred to as PA-X-Ys, in which $X$ and $Y$ represent the final charring temperature (300, 400 , and $\left.500^{\circ} \mathrm{C}\right)$ and the $R(0,0.25,0.5$, and 1.0$)$, respectively. Each sample was heated up to a designed temperature and kept at this temperature for 1 hour at a heating rate of $10^{\circ} \mathrm{C} / \mathrm{min}$. The Brunauer-Emmett-Teller (BET) surface areas $\left(S_{\mathrm{BET}}\right)$ of BCs were measured by the adsorption of $\mathrm{N}_{2}$ at $77 \mathrm{~K}$ in a surface area analyzer (Quantachrome Corporation, USA). The $S_{\mathrm{BET}}$ was also calculated from the isotherms in the BET equation. The surface textures of the BCs were observed by a scanning electron microscope (SEM Hitachi S4800, Japan). The surface functional groups of BCs were defined by using Boehm's titration method.

Adsorption experiments were conducted with the initial concentration of $\mathrm{Ni}(\mathrm{II})$ in the range of $10-60 \mathrm{mg} / \mathrm{L}$. The adsorption dose was $600 \mathrm{mg} / \mathrm{L}$ using $100 \mathrm{~mL}$ flask. The initial $\mathrm{pH}$ was adjusted with addition of $0.01 \mathrm{M} \mathrm{HCl}$ or $\mathrm{NaOH}$ to the value of $6.00 \pm 0.02$. The flasks were kept in an isothermal water bath and agitated at $180 \mathrm{rpm}$ for 36 hours to ensure that equilibrium was reached. The amount of $\mathrm{Ni}(\mathrm{II})$ adsorbed at equilibrium $\left(Q_{e}, \mathrm{mg} / \mathrm{g}\right)$ was calculated by

$$
Q_{e}=\frac{\left(C_{0}-C_{e}\right) V}{W}
$$

in which $C_{0}$ and $C_{e}$ represent the initial and equilibrium concentration of $\mathrm{Ni}(\mathrm{II})(\mathrm{mg} / \mathrm{L})$, respectively; $V$ is the solution volume (L); and $W$ is the mass of adsorbent (g).

\section{Results and Discussion}

Figure 1 shows the thermogravimetric analysis of $\mathrm{PA}-X-Y$ samples. It can be seen from TGA curves that PA- $X-Y(Y>0)$ samples displayed much lower weight loss than PA- $X-0$ samples, indicating that APP has good flame retardant performance for PA. The yields of BCs, as listed in Table 1, were defined as the ratio of the weight of produced $\mathrm{BC}$ to the weight of PA used for charring. Yields of the BCs declined with increasing temperature and increased with increasing the amount of APP added. The yields of BC-X-Y $(Y>0)$ were dramatically much higher than $\mathrm{BC}-X-0$, which also confirmed that APP used as fire retardant played a key role in BCs preparation.

The weight loss for the samples during thermogravimetric analysis could be divided into three stages. In the first stage, the small amount of weight loss was caused by loss of water and light volatile compounds in PA with the temperature rising from room temperature to $200^{\circ} \mathrm{C}$. Then, a significant weight loss occurred with temperature from $200^{\circ} \mathrm{C}$ to the final temperature $\left(300,400\right.$, or $\left.500^{\circ} \mathrm{C}\right)$, which was mainly caused by evolution of volatile compounds generated by decomposition of hemicellulose, cellulose, and lignin in PA. In the last stage, as temperature kept at a constant value of 300,400 , or $500^{\circ} \mathrm{C}$, the samples displayed a continuous and slight weight loss. In the chemical reaction of PA with APP, PA is in the reducing atmosphere resulting from the formation of carbonization layer promoted by the presence of APP. Thereby, the char of PA is promoted at the high temperature in the muffle furnace. Besides, with the increase of temperature, APP can decompose into $\mathrm{H}_{3} \mathrm{PO}_{4}$ and phosphates. The fire retardation and dehydration condensation in reaction of $\mathrm{H}_{3} \mathrm{PO}_{4}$ with lignocellulose also contribute to the char of PA $[8,9]$.

SEM micrographs of the BCs are shown in Figure 2. After carbonization without APP, BCs showed a similar structure to PA, while the structure of BC-400-0.5 was obviously corroded. Some particles or flakes on the surfaces of BC400-0.5 were observed, which could result from the chemical vapor deposition of pyrolysis products. As shown in Table 1, the BET surface area of $\mathrm{BC}-X-0$ samples increased with increasing pyrolysis temperature. The production of volatile compounds inside PA particles gradually increased as the final temperature rises, which caused increase of porosity. Obviously, it could be drawn that the $S_{\mathrm{BET}}$ of $\mathrm{BC}-X-Y(Y>$ 0 ) were higher than that of $\mathrm{BC}-X-0$, indicating that APP as a fire retardant was efficient to pore-forming in BCs preparation. And the results of Boehm's titrations were also showed in Table 1 . The surface acidity of BC-X-Y $(Y>$ 0 ), carboxyl, in particular, was much more than BC-X-0. This demonstrated that phosphoric acid was released by APP in BCs preparation. The previous researches indicated that the active surface acidic characteristic of carbons could contribute to adsorption of heavy metal [10]. Therefore, the $\mathrm{Ni}$ (II) adsorption of BCs would be improved.

The adsorption isotherms of $\mathrm{Ni}(\mathrm{II})$ onto the BCs, as shown in Figure 3, were analyzed at different initial $\mathrm{Ni}$ (II) concentrations varying from 10 to $60 \mathrm{mg} / \mathrm{L}$. In order to estimate the maximum adsorption capacity of $\mathrm{Ni}$ (II) onto the BCs, both of Langmuir (2) and Freundlich (3) isotherm models were conducted to simulate the sorption:

$$
\begin{aligned}
& Q_{e}=\frac{Q_{m} K_{\mathrm{L}} C_{e}}{1+K_{\mathrm{L}} C_{e}}, \\
& Q_{e}=K_{\mathrm{F}} C_{e}^{1 / n} .
\end{aligned}
$$




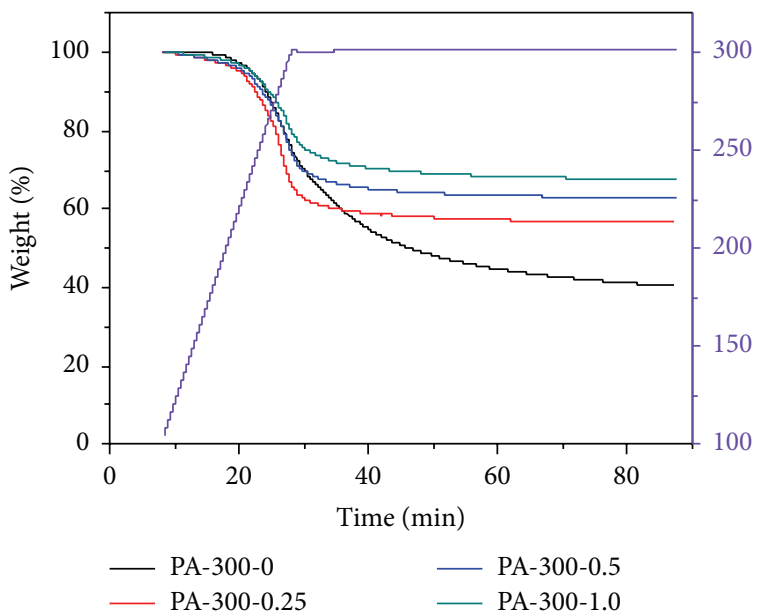

(a)

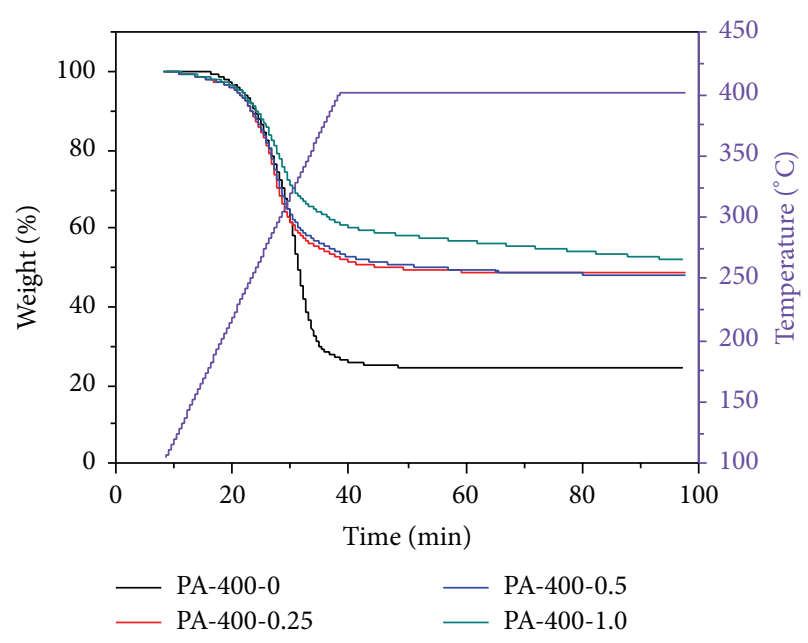

(c)

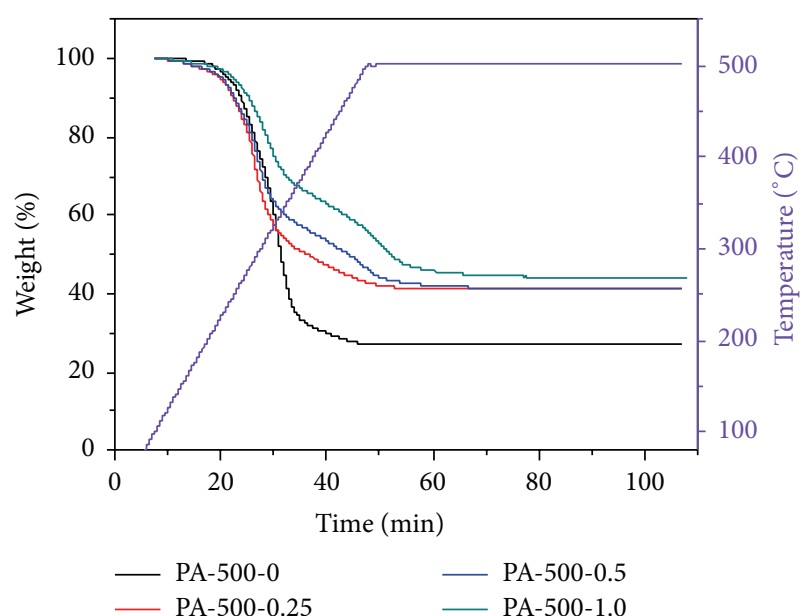

(e)

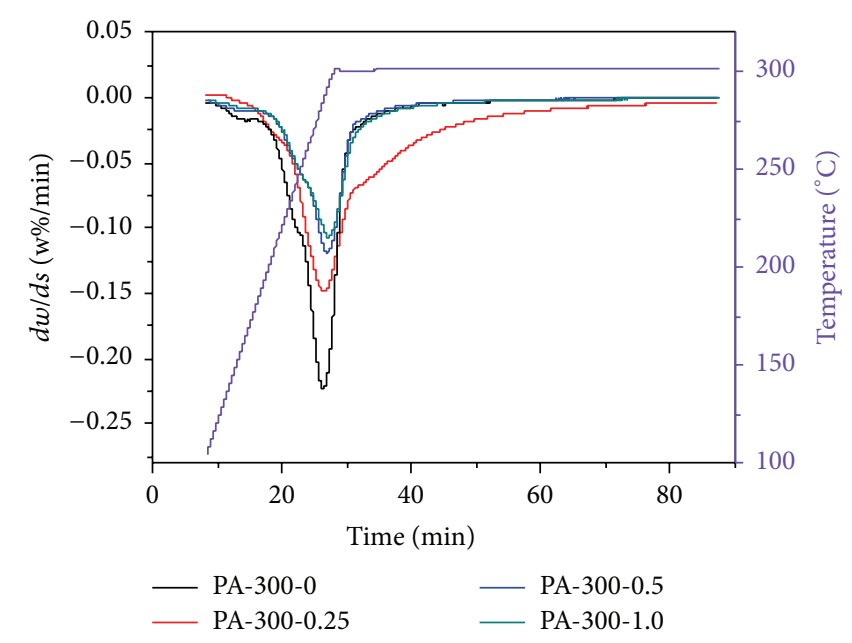

(b)

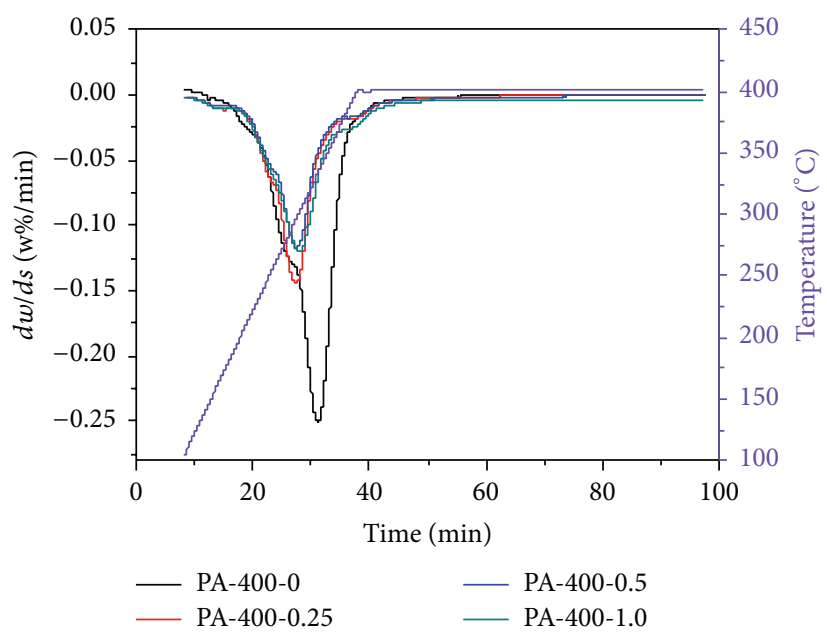

(d)

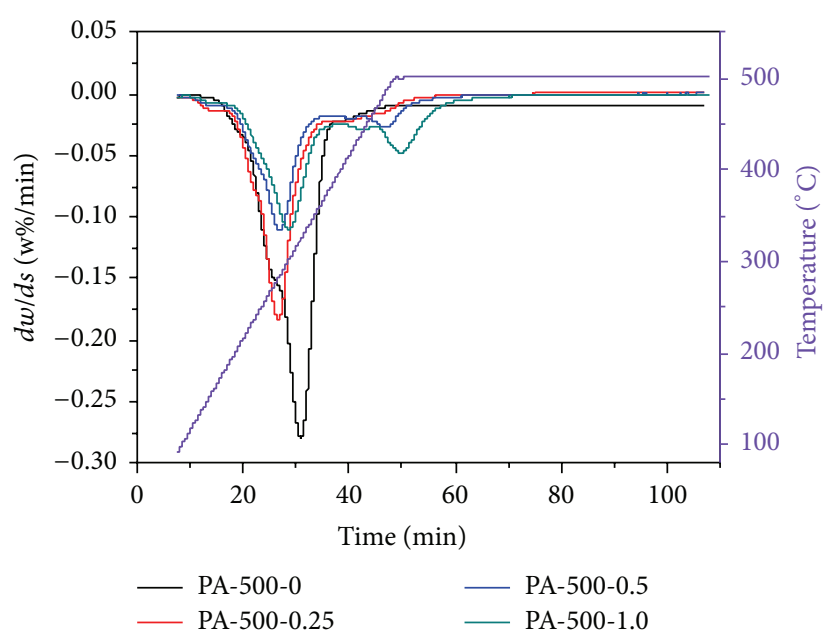

(f)

FIGURE 1: Thermogravimetric analysis (TGA) and derivative thermogravimetric (DTG) curves of PA- $X-Y$ samples. (a) TGA curves of PA300-Y samples; (b) DTG curves of PA-300-Y samples; (c) TGA curves of PA-400-Y samples; (d) DTG curves of PA-400-Y samples; (e) TGA curves of PA-500- $Y$ samples; (f) DTG curves of PA-500- $Y$ samples. 


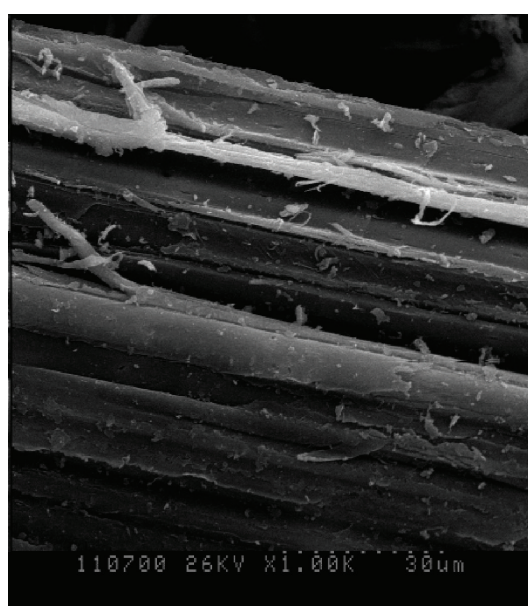

(a)

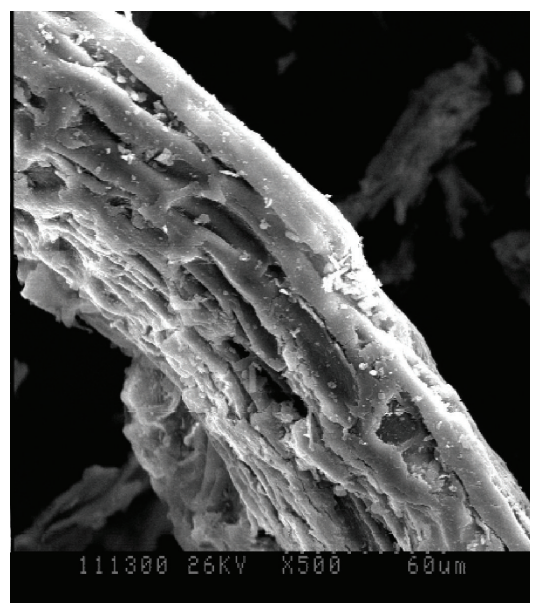

(c)

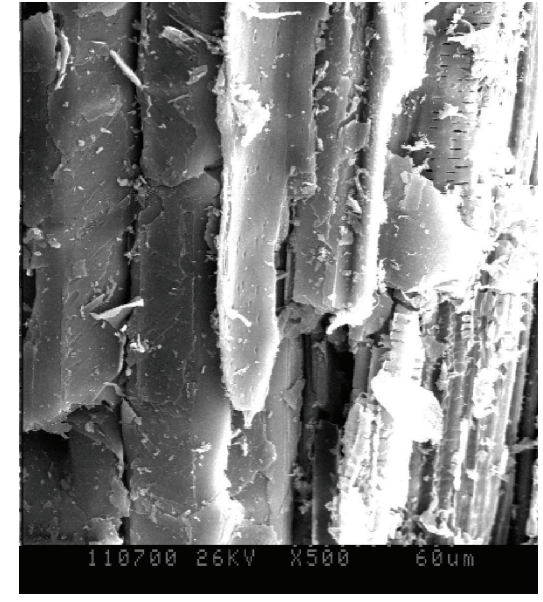

(b)

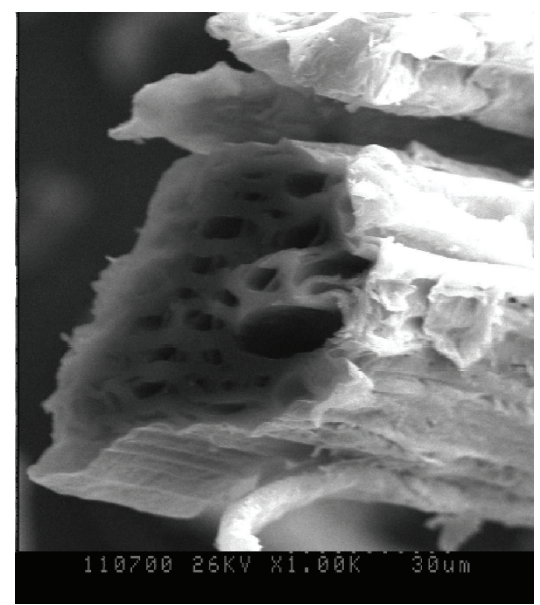

(d)

FIgURE 2: SEM micrographs of (a) PA sample, (b) BC-400-0 sample, and (c and d) BC-400-0.5 sample.

TABLE 1: Surface area, yields and surface functional groups of the BC samples.

\begin{tabular}{|c|c|c|c|c|c|c|}
\hline Samples number & $S_{\mathrm{BET}}\left(\mathrm{m}^{2} / \mathrm{g}\right)$ & Yield (\%) & Carboxyl (mmol/g) & Lactone $(\mathrm{mmol} / \mathrm{g})$ & Phenolic (mmol/g) & $\begin{array}{c}\text { Total acidic } \\
\text { functional groups } \\
(\mathrm{mmol} / \mathrm{g})\end{array}$ \\
\hline BC-300-0 & 4.6 & 29.5 & 0.1964 & 0.3217 & 0.5741 & 1.0922 \\
\hline BC- $-300-0.25$ & 167.9 & 56.0 & 0.3011 & 0.3719 & 1.1727 & 1.8457 \\
\hline BC-300-0.5 & 164.3 & 58.6 & 0.3036 & 0.2936 & 0.8999 & 1.4971 \\
\hline BC-300-1.0 & 151.7 & 66.8 & 0.2992 & 0.3300 & 0.8419 & 1.4711 \\
\hline BC- $400-0$ & 7.9 & 25.1 & 0.1841 & 0.2709 & 0.6449 & 1.0999 \\
\hline BC-400-0.25 & 177.7 & 48.0 & 0.3661 & 0.3284 & 1.0713 & 1.7657 \\
\hline BC- $400-0.5$ & 181.2 & 53.8 & 0.3663 & 0.3575 & 0.9701 & 1.7121 \\
\hline BC-400-1.0 & 171.4 & 57.8 & 0.3858 & 0.3359 & 0.9469 & 1.6686 \\
\hline BC-500-0 & 12.1 & 16.5 & 0.0790 & 0.4102 & 0.4923 & 0.9815 \\
\hline BC-500-0.25 & 165.8 & 43.4 & 0.6180 & 0.1099 & 1.1835 & 1.9744 \\
\hline BC-500-0.5 & 149.5 & 50.4 & 0.3567 & 0.3615 & 1.0829 & 1.8012 \\
\hline BC-500-1.0 & 157.2 & 54.8 & 0.5329 & 0.1220 & 0.9919 & 1.6469 \\
\hline
\end{tabular}




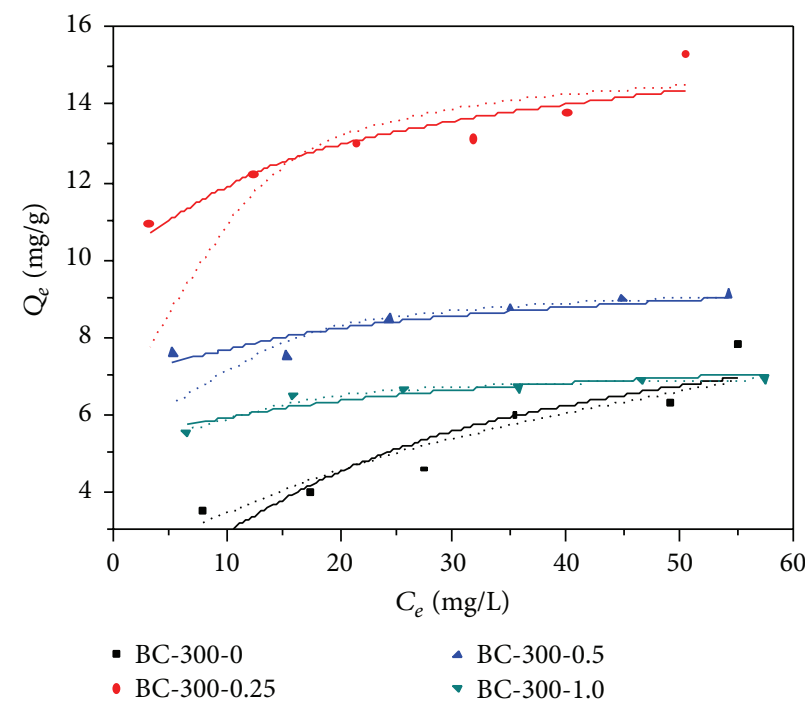

(a)

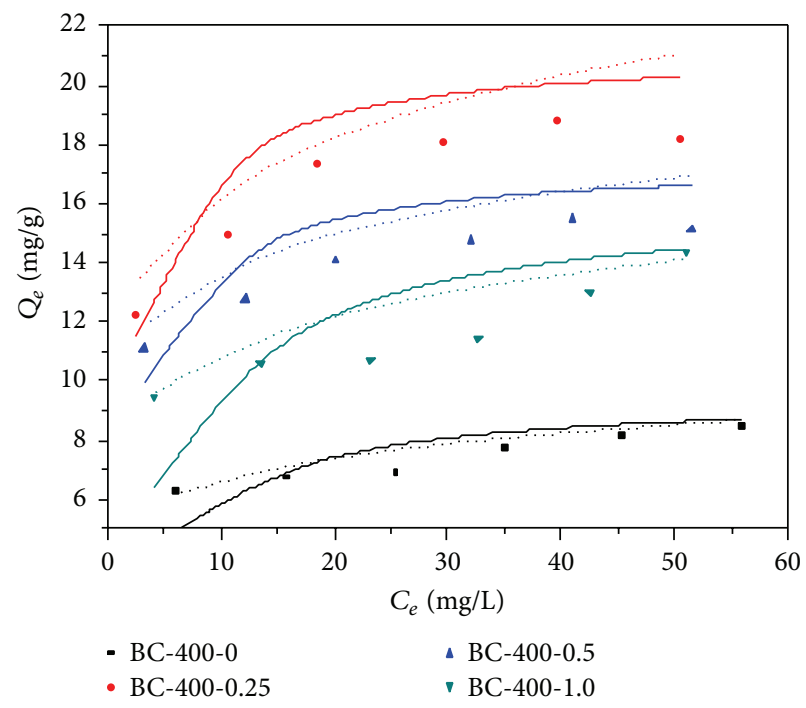

(b)

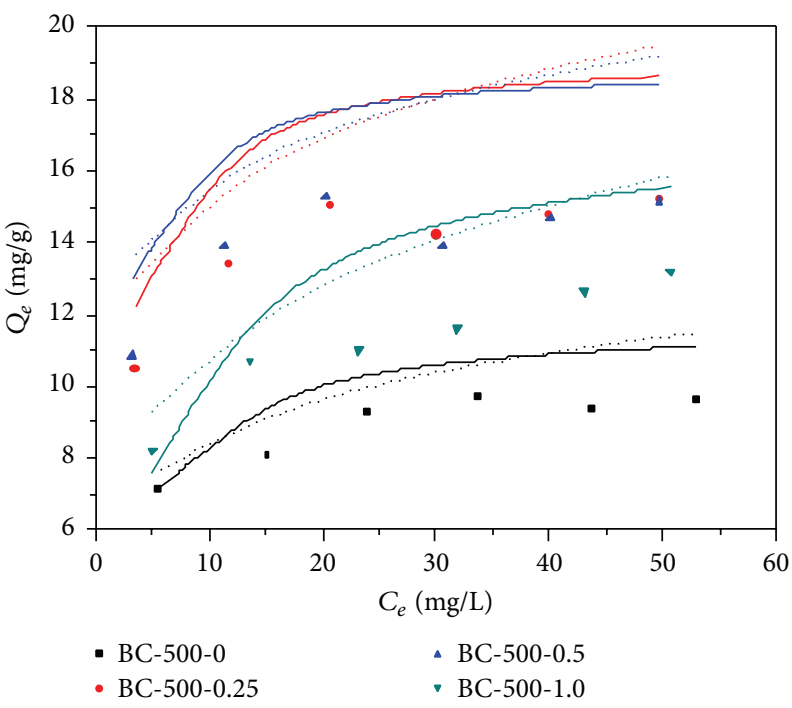

(c)

FIgURE 3: Sorption isotherms of Ni(II) on the BCs. (a) BC-300-Y samples; (b) BC-400-Y samples; (c) BC-500-Y samples.

Here, $Q_{e}$ represents the absorption amount $(\mathrm{mg} / \mathrm{g}) ; C_{e}$ represents the equilibrium concentration $(\mathrm{mg} / \mathrm{L}) ; Q_{m}$ represents the maximum sorption capacity $(\mathrm{mg} / \mathrm{g}) ; K_{\mathrm{L}}$ represents the Langmuir sorption constant; and $K_{\mathrm{F}}$ and $1 / n$ are the Freundlich constants.

The constants of both models fitting into the adsorption data were presented in Table 2. The correlation coefficient $\left(R^{2}\right)$ in Langmuir model were much higher than those obtained from Freundlich model, indicating that the adsorption of $\mathrm{Ni}(\mathrm{II})$ on the BCs was simulated better by Langmuir model than Freundlich model. This also is observed from Figure 3 that the Langmuir model fits the data better. The $1 / n$ values of the BCs were between 0 and 1 , representing a favorable sorption of $\mathrm{Ni}(\mathrm{II})$ onto the BCs. As shown in
Table 2 and Figure 3, the adsorption capacities of $\mathrm{Ni}$ (II) onto the BC- $X-Y$ samples obtained its maximum at $Y=0.25$ (BC-300-0.25, BC-400-0.25, and BC-500-0.25) for different charring temperatures and at $X=400^{\circ} \mathrm{C}$ for different $R$. The considerable $\mathrm{Ni}(\mathrm{II})$ sorption capacity of $\mathrm{BC}-400-Y$ sample $(Y>0)$ could be attributed to the roles of the higher surface area and more acid functional groups.

\section{Conclusions}

This study investigated the preparation of BCs by using APP as flame retardant. The results indicated that, by comparing with the BC-X-0 samples, (1) enhanced the porosity and surface acidity of BCs were developed by using APP as flame 
TABLE 2: Langmuir and Freundlich constants related to the adsorption isotherms of $\mathrm{Ni}(\mathrm{II})$ for the BCs samples.

\begin{tabular}{|c|c|c|c|c|c|c|}
\hline \multirow{2}{*}{ Samples number } & \multicolumn{3}{|c|}{ Langmuir } & \multicolumn{3}{|c|}{ Freundlich } \\
\hline & $Q_{m}(\mathrm{mg} / \mathrm{g})$ & $K_{\mathrm{L}}(\mathrm{L} / \mathrm{mg})$ & $R^{2}$ & $1 / n$ & $K_{\mathrm{F}}\left(\mathrm{mg}^{1-n} \mathrm{~L}^{n} \mathrm{~g}^{-1}\right)$ & $R^{2}$ \\
\hline BC-300-0 & 9.7466 & 0.0451 & 0.8714 & 0.3942 & 1.4126 & 0.8888 \\
\hline BC-300-0.25 & 15.408 & 0.3169 & 0.9872 & 0.1071 & 9.4480 & 0.8983 \\
\hline BC-300-0.5 & 9.4787 & 0.3748 & 0.9975 & 0.0879 & 6.3414 & 0.8093 \\
\hline BC-300-1.0 & 7.1174 & 0.5569 & 0.9998 & 0.0957 & 4.7841 & 0.8950 \\
\hline BC- $400-0$ & 9.0090 & 0.2054 & 0.9917 & 0.1390 & 4.7119 & 0.9102 \\
\hline BC-400-0.25 & 19.231 & 0.4948 & 0.9979 & 0.1473 & 10.770 & 0.9567 \\
\hline BC- $400-0.5$ & 15.898 & 0.4565 & 0.9983 & 0.1216 & 9.6253 & 0.9766 \\
\hline BC- $400-1.0$ & 14.859 & 0.1760 & 0.9658 & 0.1438 & 7.4076 & 0.7877 \\
\hline BC-500-0 & 10.142 & 0.3728 & 0.9978 & 0.1427 & 5.6305 & 0.9224 \\
\hline BC-500-0.25 & 15.528 & 0.6002 & 0.9982 & 0.1328 & 9.3008 & 0.8772 \\
\hline BC- $500-0.5$ & 15.244 & 0.8200 & 0.9964 & 0.1098 & 10.046 & 0.7865 \\
\hline BC-500-1.0 & 14.025 & 0.2094 & 0.9932 & 0.1920 & 6.1398 & 0.9652 \\
\hline
\end{tabular}

retardant; (2) using APP as flame retardant for BC production can dramatically enhance the $\mathrm{Ni}(\mathrm{II})$ adsorption capacities of the produced BCs.

\section{Conflict of Interests}

The authors declare that there is no conflict of interests regarding the publication of this paper.

\section{Acknowledgment}

This work was supported by the China Postdoctoral Science Foundation (2013M540551).

\section{References}

[1] G. Shrestha, S. J. Traina, and C. W. Swanston, "Black carbon's properties and role in the environment: a comprehensive review," Sustainability, vol. 2, no. 1, pp. 294-320, 2010.

[2] H. Asai, B. K. Samson, H. M. Stephan et al., "Biochar amendment techniques for upland rice production in Northern Laos: 1. Soil physical properties, leaf SPAD and grain yield," Field Crops Research, vol. 111, no. 1-2, pp. 81-84, 2009.

[3] Q. Wang, H. Xie, J. Zhang et al., "Effect of plant harvesting on the performance of constructed wetlands during winter: radial oxygen loss and microbial characteristics," Environmental Science and Pollution Research, vol. 22, pp. 7476-7484, 2015.

[4] Z. Guo, X. Bian, J. Zhang et al., "Activated carbons with welldeveloped microporosity prepared from Phragmites australis by potassium silicate activation," Journal of the Taiwan Institute of Chemical Engineers, vol. 45, no. 5, pp. 2801-2804, 2014.

[5] S. Nie, Y. Hu, L. Song, Q. He, D. Yang, and H. Chen, "Synergistic effect between a Char Forming Agent (CFA) and microencapsulated ammonium polyphosphate on the thermal and flame retardant properties of polypropylene," Polymers for Advanced Technologies, vol. 19, no. 8, pp. 1077-1083, 2008.

[6] Z. Guo, J. Fan, J. Zhang et al., "Sorption heavy metal ions by activated carbons with well-developed microporosity and amino groups derived from Phragmites australis by ammonium phosphates activation," Journal of the Taiwan Institute of Chemical Engineers, vol. 58, pp. 290-296, 2016.
[7] Z. Guo, L. Xu, C. Liu, F. Sun, Y. Kang, and S. Liang, "Comparison of physicochemical properties of activated carbons derived from biomass wastes by $\mathrm{H}_{4} \mathrm{P}_{2} \mathrm{O}_{7}$ activation: adsorption of trimethoprim," Desalination and Water Treatment, 2015.

[8] M. Molina-Sabio, C. Almansa, and F. Rodríguez-Reinoso, "Phosphoric acid activated carbon discs for methane adsorption," Carbon, vol. 41, no. 11, pp. 2113-2119, 2003.

[9] M. A. Nahil and P. T. Williams, "Pore characteristics of activated carbons from the phosphoric acid chemical activation of cotton stalks," Biomass and Bioenergy, vol. 37, pp. 142-149, 2012.

[10] H. Liu, S. Liang, J. Gao et al., "Development of biochars from pyrolysis of lotus stalks for $\mathrm{Ni}(\mathrm{II})$ sorption: using zinc borate as flame retardant," Journal of Analytical and Applied Pyrolysis, vol. 107, pp. 336-341, 2014. 

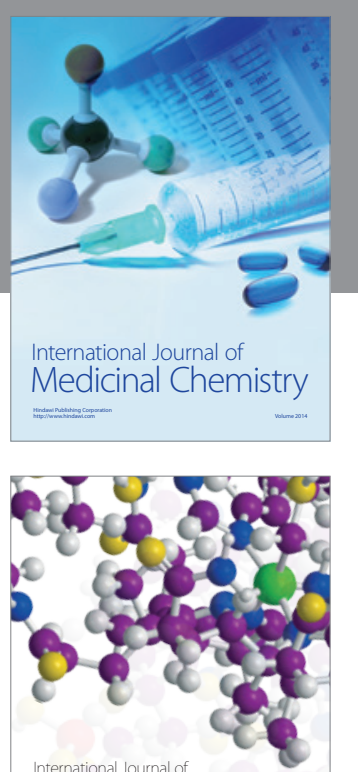

Carbohydrate Chemistry

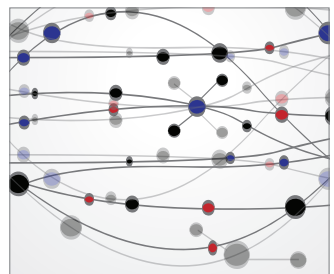

The Scientific World Journal
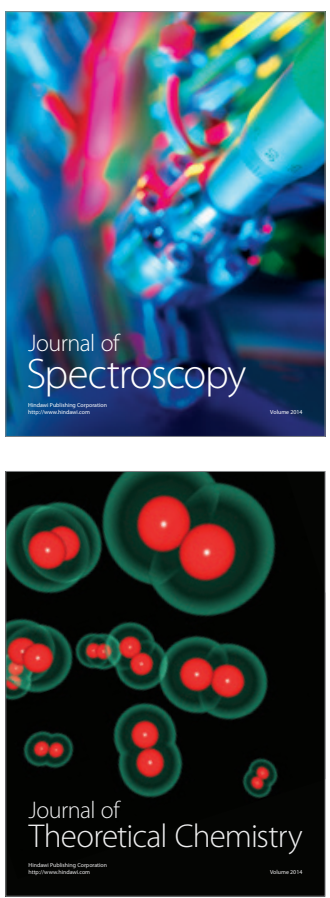
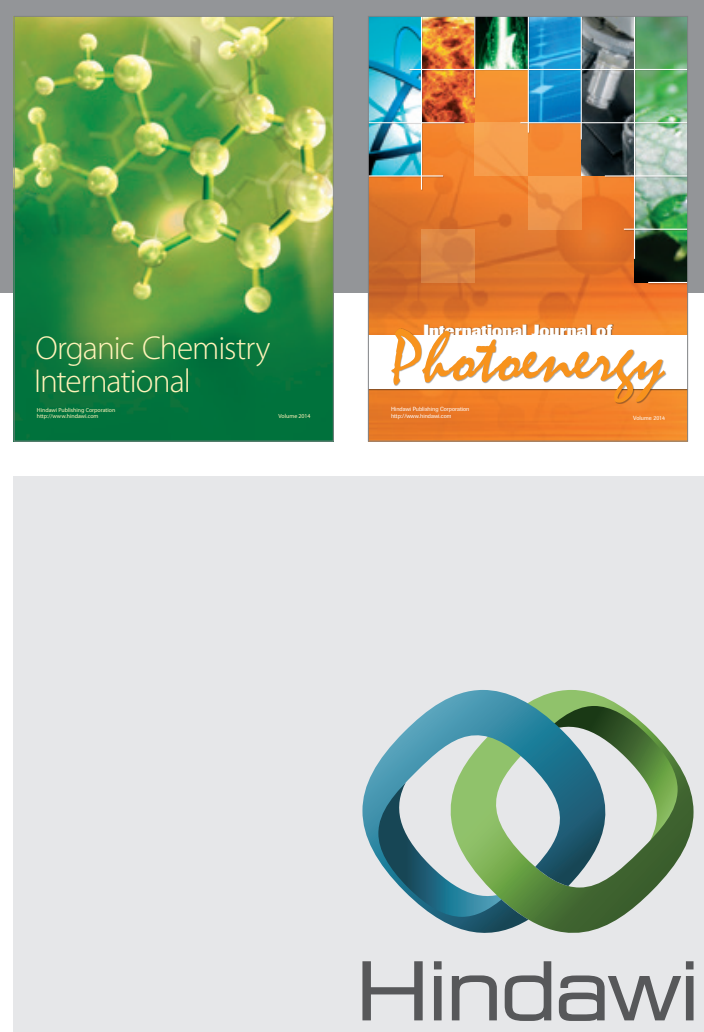

Submit your manuscripts at

http://www.hindawi.com

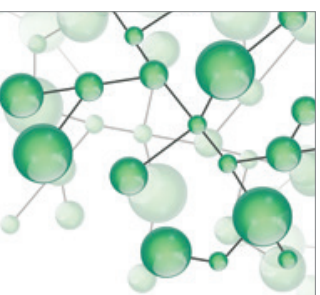

International Journal of

Inorganic Chemistry

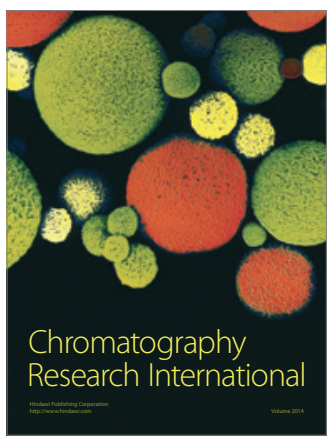

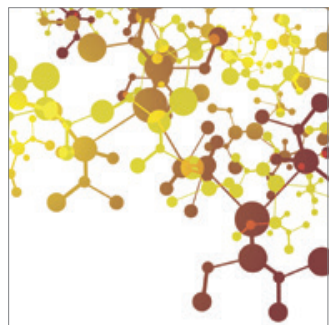

Applied Chemistry
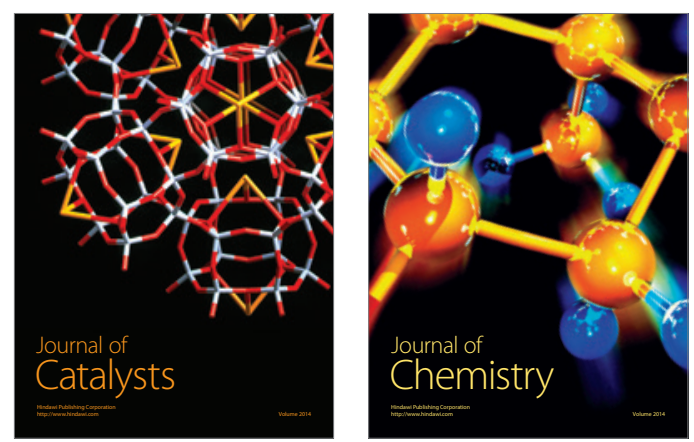
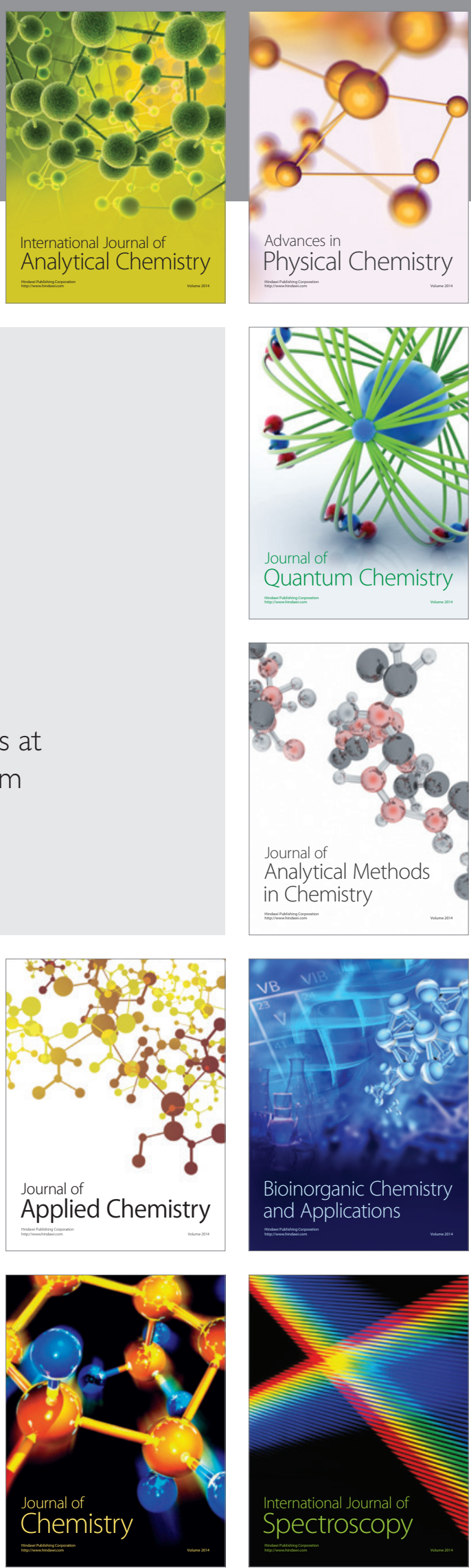